\title{
Resource-saving technology for oily wastewater treatment in agro-industrial complexes
}

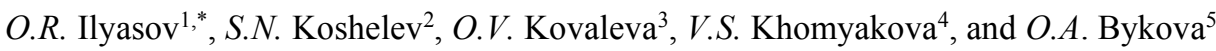 \\ ${ }^{1}$ FSBSI Ural Federal Agrarian Research Center of the Ural Branch of the Russian Academy of \\ Sciences, Yekaterinburg, Russia \\ ${ }^{2}$ FSBEI HE Kurgan State Agricultural Academy n.a. T.S. Maltsev, Kurgan, Russia \\ ${ }^{3}$ FSBEI HE State Agrarian University of the Northern Trans-Urals, Tyumen, Russia \\ ${ }^{4}$ FSBEI HE Ural State University of Railway Engineering, Yekaterinburg, Russia \\ ${ }^{5}$ FSBEI HE Ural State Agrarian University, Yekaterinburg, Russia
}

\begin{abstract}
The authors of the article consider the problem of protection of water bodies from pollution by oily wastewater from the territory of enterprises of the agro-industrial complex engineering and technical systems. A resource-saving technology for this wastewater treatment using multicomponent sorbents has been developed.
\end{abstract}

\section{Introduction}

One of the main categories of wastewater at the enterprises of engineering and technical systems of the agro-industrial complex (hereinafter referred to as AIC) is oil-containing effluents, which are persistent emulsions of the "oil in water" type, the main component of which is used lubricating and cooling technical agents (hereinafter referred to as OSOTS) and compositions of used detergents.

OSOTS are used in the mechanical processing of metals at enterprises for the maintenance of technical means of production for the agro-industrial complex.

In the AIC, OSOTS are used not only as a lubricant and cooling agent, but also as a protection against corrosion as a result of the film formed on the surface, as well as improving the quality of the treated surface.

It should be noted that OSOTS with all their advantages and multifunctional use have a significant disadvantage, which is associated with a large number of emulsifiers that protect OSOTS from delamination, but make the disposal of OSOTS extremely costly and difficult.

Getting into the wastewater, such OSOTS represent a serious problem for treatment facilities [1]. It is extremely important that these wastewaters are treated by special methods and only after this stage of preliminary treatment are sent to the drain well or to the treatment facilities [2].

In case of situations when spent OSOTS fall into water bodies, the following types of pollution are formed: petroleum/oil film, heavy fractions of dissolved and emulsified petroleum products/oils, settle to the bottom, etc. Water changes primarily in organoleptic parameters, changes in physical and chemical quality indicators, dangerous organic

\footnotetext{
* Corresponding author: ilyasov3@rambler.ru
} 
compounds are formed, and water resources may become unsuitable for the existence of hydrobionts and the aquatic environment as a whole, for use in economic activities.

Based on the above, a promising direction of research is to find the most effective and environmentally friendly ways to neutralize OSOTS, the relevance is not in doubt.

Purpose and objectives. The purpose of the research was to develop a resource-saving technology for the treatment of industrial wastewater from the territory of enterprises of engineering and technical systems of the agro-industrial complex. To achieve this goal, it was necessary to solve a number of tasks:

- assessment of industrial oil-containing wastewater impact on environmental components.

- $\quad$ research of existing technologies for emulsion wastewater treatment.

- development of resource-saving technology for the treatment of emulsion wastewater from the territories of engineering and technical systems of the agro-industrial complex.

\section{Methods and materials}

To achieve this goal and objectives, theoretical research (literature review, patent search, data analysis, selection of research methods, etc.), experimental (laboratory tests to study the flotation processes of multicomponent sorbents) and desk research (analysis and processing of the results) were used. The research is based on the use of a set of generally accepted methods.

\section{Research results}

Within the framework of the conducted studies, various options were studied in depth that determine the choice of certain effluents treatment, the determining indicators were the following - the real concentration of petroleum products and oils in the effluents, including other impurities, the flow rate, the reference indicators of treated water quality, considering the requirements of the standards (for all pollutants and components). It should be noted that the results and the degree of treatment can be significantly affected by the storage and transportation conditions of OSOTS, which can significantly complicate the treatment process.

Thus, the degree of treatment is determined by the quality indicators required for water, the conditions of storage, transportation and previous use of OSOTS, economic characteristics, which in turn determines the technological scheme of wastewater treatment.

Let's take a closer look at the process of using reagents based on activated minerals [3] for the neutralization of various types of emulsion wastewater within the sorptionflocculation treatment method, and the choice of this type of materials is caused by the following:

- chemical resistance and mechanical strength;

- high sorption capacity, which ensures the removal of suspended particles, colloidal substances of mineral and organic origin, sorption of cations and anions;

- have a low cost, significantly different from the cost of synthetic sorbents [4].

During the experimental studies, the compositions of multicomponent sorption reagents using: montmorillonite, palygorskit, diatomite, gaize are considered. Emulsion wastewater was treated on the basis of synthetic emulsifiers and vegetable oils. These emulsifiers were used in the processes of hot sheet and pipe rolling production. The use of various minerals in a ratio of up to $50 \%$ allowed to optimize the compositions and experimentally establish treatment modes, as a result of which the following indicators were obtained: 
- particle settling rate $-0.3-0.8 \mathrm{~mm} / \mathrm{s}$;

- sediment volume - 5-15\%;

- residual content of petroleum products $<0.05-0.3 \mathrm{mg} / \mathrm{dm}^{3}$;

- anionic surfactants - $0.1-0.6 \mathrm{mg} / \mathrm{dm}^{3}$;

- total salinity - comparable to industrial water salinity;

- chemical oxygen consumption - 30-550 $\mathrm{mg} \mathrm{O}_{2} / \mathrm{dm}^{3}$.

During industrial tests, the decomposition of emulsions was technologically carried out according to a two-agent scheme using compositions of multicomponent sorbents containing finely ground gaize and representing a generally hydrophobic-hydrophilic complex compound based on mixed organo-mineral activation of aluminosilicates, and high-molecular-weight ionogenic polyelectrolyte. In the two-agent scheme (during sorption-flocculation decomposition), the use of coagulants (aluminum tetraoxosulfate (VI), Iron (II) sulfate, iron chloride (III), aluminum polyoxychloride, etc.), acids (hydrochloric and sulfuric acids, etc.) and alkalis (sodium hydroxide and potassium hydroxide, etc.) is completely excluded from the technological process of emulsion decomposition, and the decomposition process takes place within 20 minutes.

The proposed OSOST treatment system allows not only to obtain treated waste water with a low residual content of petroleum products $<3.00 \mathrm{mg} / \mathrm{dm}^{3}$ (with particles with a hydraulic fineness $<2.00 \mathrm{~mm} / \mathrm{sec}$ ), but also to obtain easily ignited oil sludge at the output, which belongs to the waste of hazard class 4 (according to the FCCW) and can easily be neutralized.

Clarified water obtained as part of wastewater treatment can be reused in the recycling systems of enterprises, for the preparation of initial working emulsions, etc. A positive feature of the method for almost any emulsion is that it is not necessary to increase the temperature during sorption-flocculation decomposition, the entire process is performed at ambient temperature, so the unit cost per $1 \mathrm{~m}^{3}$ of the emulsion varies from 15 to 150 rubles. This proves the economic feasibility of this method of wastewater treatment.

The comprehensive effectiveness of the proposed technology and methods for OSOTS treatment is considered in separate studies $[8,9,10,11]$, which confirm the possibility of decomposition of almost any emulsion, regardless of the degree of its stability, composition and type of emulsifiers and stabilizers used in its composition.

The development of the technology of reagent treatment of oil-emulsion wastewater is an adaptive variation to the existing capabilities of various industries and existing equipment. But whatever the specifics of production, the overall technological solution of the basic hardware design remains constant.

The scheme of the general technological solution of the basic hardware design, based on the possible processing methods, is as follows:

- waste oil-emulsion effluents are accumulated in the averaging tank, are sent to the reagent decomposition unit;

- a suspension of the working concentration is prepared from a dry commercial reagent and is fed by metering pumps to the reagent decomposition unit;

- a solution of a flocculating agent of working concentration is prepared from a dry commercial reagent and is fed by metering pumps to the reagent decomposition unit;

- in the reagent decomposition unit, it interacts with sorption-flocculation agents and decomposes the emulsion into clarified water and sludge;

- from the reagent decomposition unit of oil-emulsion wastewater, the resulting sludge and clarified water are fed to the settling tank where their sedimentation separation occurs.

The "SF-A2" reagent in the "M8" modification was tested at OJSC Magnitogorsk Iron and Steel Works in the sheet rolling shop No. 8. For this purpose, an effective version of the technological method for the reagent decomposition of spent emulsions based on the emulsifiers "Quakerol 403A" and "Henkel 5553" was developed. 


\section{Conclusions}

The technological scheme of the process of neutralizing emulsions involves a two-stage treatment with sorption-flocculation reagents. The decomposition process proceeds without changing the temperature and the qualitative composition of the initial effluents. The estimated amount of oil-emulsion effluents at peak load is $120 \mathrm{~m}^{3}$ per day or $15 \mathrm{~m}^{3}$ per hour. Data on the qualitative composition of the initial oil-emulsion wastewater and the quality of clarified water are recorded in the log located at the Recycling unit for cooling mixture. Clarified water after treatment is discharged into the settling tank of the plant circulating water supply system or can be used to prepare an emulsion of working concentration. For sanitary treatment of equipment and communications of treatment facilities, it is necessary to provide for the possibility of periodic treatment of the system with calcium hypochlorite $\mathrm{Ca}(\mathrm{C} 1 \mathrm{O})_{2}$. Sludge (oil sludge), dewatered by vacuum filtration, with a humidity of $50-55 \%$ is exported to the landfill of industrial waste.

Thus, the use of multicomponent sorbents in resource-saving technology for the treatment of emulsion wastewater will solve the serious problem of the negative impact of ecotoxicants of this effluent on the environment.

\section{References}

1. L.I. Kuzubova, S.V. Morozov, Treatment of oily wastewater. Analytical review, Russian Academy of Sciences. Siberian branch. State Public Scientific and Technical Library. 60 (Novosibirsk Institute of Organic Chemistry, Novosibirsk, 1992)

2. O.R. Ilyasov, Biosecurity of water sources in agricultural catchments from pollution by effluents from poultry farming enterprises, Dissertation for the degree of Doctor of Biological Sciences, Yekaterinburg, (2004)

3. Yu.A. Tarasevich, Natural sorbents in the process of water purification 205 (Kiev, Naukova Dumka,1981)

4. O.R. Ilyasov, Protection of water sources from contamination by surface runoff of residential areas using the biosorption method, Diss. cand. tech. sc., Yekaterinburg, 150 (2002) 